\title{
A donor twin discordant with Peters anomaly in a twin-twin transfusion syndrome case: a case report
}

\author{
Yao-Lung Chang ${ }^{1 *} \mathbb{D}$, An-Shine Chao ${ }^{1}$, Ching-Yu Chou², Shuenn-Dyh Chang ${ }^{1}$, Ming-Chou Chiang ${ }^{3}$ and \\ Yung-Sung Lee ${ }^{4}$
}

\begin{abstract}
Background: Peters anomaly is a rare form of anterior segment ocular dysgenesis, the antenatal image of Peters anomaly had not been reported. We herein showcased a discordant finding of Peters anomaly in a monozygotic twin complicated with twin-twin transfusion syndrome (TTS) and exhibited its antenatal sonographic images,

Case presentation: A 38-year-old gravida 2 para 1 pregnant woman visited our clinic at the gestational age of 18 weeks where TTS stage III was diagnosed and the following laser therapy was done successfully. Ten days after the surgery, the follow-up ultrasound detected the opacity of both fetal eyeballs in the donor twin and thus congenital cataract was suspected initially. Then magnetic resonance imaging (MRI) examination was arranged at the gestational age of 23 weeks, and no central nervous system or other anomaly was found. At the 29 weeks of gestation, the opacity of both fetal eyeballs of the donor twin did not clear. The pregnancy resulted in cesarean section at the gestational age of 37 weeks indicated by malpresentation where two male live births were born. Examination under anesthesia was arranged for donor twin after delivery and Peters anomaly was diagnosed based on central corneal opacity with iridocorneal and corneolenticular adhesions.

Conclusions: The prenatal image of Peters anomaly may present as the opacity of the fetal eyeballs similar to congenital cataract. Some cases of the Peters anomaly had been reported with a genetic abnormality, but since our case presented discordant presentation in monozygotic twin pregnancy where both twins are supposed to share the same genetic make-up, therefore other factors that are epigenetic may be held accountable. Nevertheless, a genetic origin of the anomaly in our case cannot be excluded.
\end{abstract}

Keywords: Peters anomaly, Monochorionic twin, Case report

\section{Background}

Peters anomaly (PA) is a rare form of anterior segment dysgenesis characterized by corneal opacity with or without iridocorneal and/or corneolenticular adhesions [1]. It has been subdivided into type I and type II and Peters plus syndrome [2]. Peters plus syndrome is associated

\footnotetext{
* Correspondence: j12054@cgmh.org.tw

'Department of Obstetrics and Gynecology, Chang Gung Memorial Hospital, Chang Gung University College of Medicine, Tao-Yuan, Taiwan

Full list of author information is available at the end of the article
}

with cleft lip/palate, short stature, abnormal external ears and mental retardation [2]. The systemic anomalies of Peters plus syndrome can be detected by prenatal image study like sonography, [3] but PA type I and type II, owing to being characterized by localized ocular abnormalities, were never reported with prenatal image diagnosis. Some PA cases had been studied to reveal genetic defects [1], but a majority of them lacked a genetic diagnosis [4]. We reported a case of monohorionic twin complicated with twin-twin transfusion syndrome

C C The Author(s). 2020 Open Access This article is licensed under a Creative Commons Attribution 4.0 International License, which permits use, sharing, adaptation, distribution and reproduction in any medium or format, as long as you give appropriate credit to the original author(s) and the source, provide a link to the Creative Commons licence, and indicate if changes were made. The images or other third party material in this article are included in the article's Creative Commons licence, unless indicated otherwise in a credit line to the material. If material is not included in the article's Creative Commons licence and your intended use is not permitted by statutory regulation or exceeds the permitted use, you will need to obtain permission directly from the copyright holder. To view a copy of this licence, visit http://creativecommons.org/licenses/by/4.0/ The Creative Commons Public Domain Dedication waiver (http://creativecommons.org/publicdomain/zero/1.0/) applies to the data made available in this article, unless otherwise stated in a credit line to the data. 
(TTTS). The prenatal sonography 10 days after fetoscope-guided laser therapy showed opacity of fetal eyeballs in the donor twin and after delivery, the twin was diagnosed with discordant PA.

\section{Case report}

A 38 -year-old gravida 2 para 1pregnant woman was referred to our prenatal clinic for a survey at 18 weeks of gestation due to twin pregnancy with the discordant amniotic fluid amount. Sonographic examination revealed polyhydramnios with a maximum vertical pocket (MVP) of $12 \mathrm{~cm}$ in the recipient fetus's sac and another stuck twin fetus showing an absence of end-diastolic velocity of umbilical artery (UA) Doppler flow and thus a stage III TTTS was diagnosed. After consultation with the family about treatment options including amnioreduction and laser therapy, the patient chose to receive fetoscope-guided laser therapy. Under local anesthesia and following procedures as previously described [5], ten intertwin anastomoses (six donor artery to recipient vein anastomoses and four recipient vein to donor artery anastomoses) were coagulated with $10 \sim 15 \mathrm{~W}$ Diode laser power with Solomen technique. The postoperative course was uncomplicated and the UA Doppler returned to normal in donor twin after the surgery.

Ten days after the laser surgery, high-level ultrasound was done at the previous hospital that referred the case. Both fetuses had their amniotic fluid returning to normal, but incidentally they found both eyeballs of the donor twin were opaque, while the recipient's were clear. (Fig. 1) Therefore, discordant congenital cataract was suspected in the donor twin. At the gestational age of 23 weeks, fetal magnetic resonance imaging (MRI) was arranged to evaluate the central nervous system for both fetuses and to rule out if the donor twin had other associated anomalies; no additional information was gathered about the donor twin. At the gestational age of 27 weeks, sonography still revealed opacity over donor twin eyeballs. (Fig. 2) The pregnancy was completed at gestational age 37 weeks by cesarean delivery indicated by malpresentation, resulting in the birth of two male babies, both babies weighing $2460 \mathrm{~g}$ each. Ten days after delivery by examination under anesthesia, the slit lamp biomicroscopy detected an annular opacity in the central cornea over the bilateral eyes of the donor twin. Ultrasound biomicroscopy also revealed extensively iridocorneal and corneolenticular adhesions, hence establishing the diagnosis of PA. Since patients with PA have a higher likelihood of glaucoma or amblyopia during infancy or toddler period, this PA baby was regularly followed up at our ophthalmology clinic. Trabeculotomy or angle surgery will be performed if glaucoma occurs; alternative treatments include medications and cyclodestructive procedures. Corneal transplantation is also a feasible option for this baby, depending on the extent of amblyopia, to improve his vision.

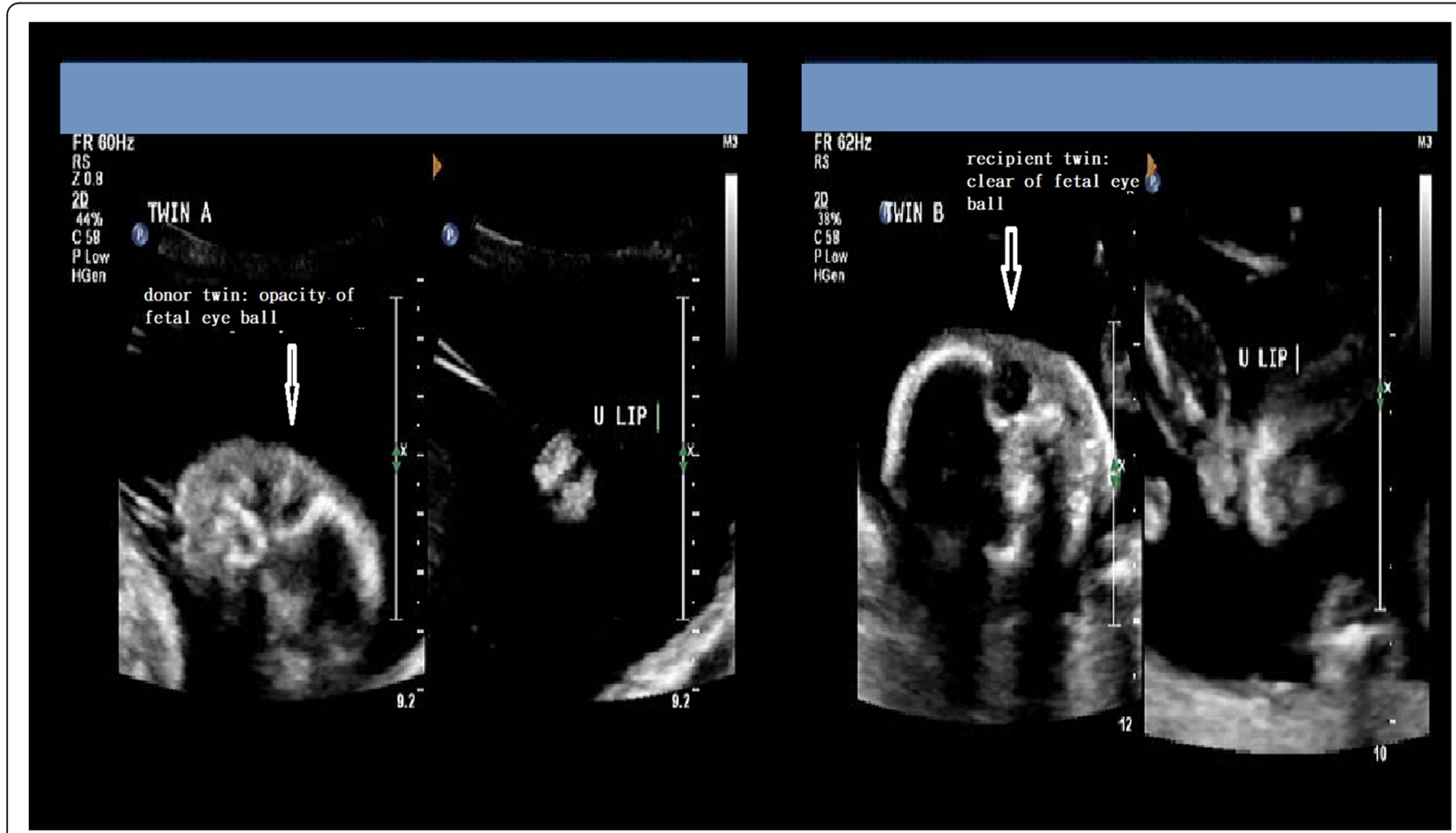

Fig. 1 Opacity of donor twin (twin a) eye ball and clear eye ball of recipient twin (twin b) found ten days after laser therapy 


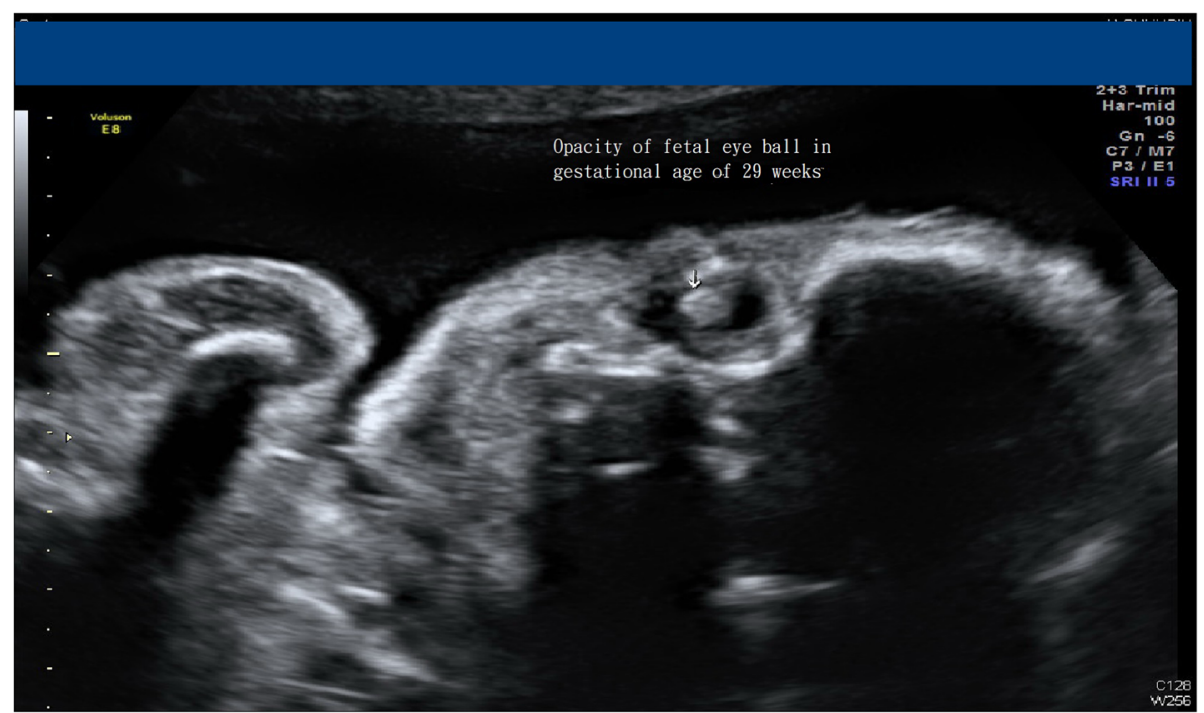

Fig. 2 Opacity of donor twin (twin a) eye ball still be found at gestational age of 29 weeks

\section{Discussion and conclusion}

We report a case of discordant PA in a monochorionic twin pregnancy complicated with TTTS, where the prenatal ultrasound images discovered opacity of donor eyeballs.

PA occurs between the 6th and 9th week of gestational age due to faulty separation of the lens from the surface ectoderm or aberrant reattachment of the lens/iris to the cornea during the development of the anterior chamber [6]. PA is characterized by the presence of a central corneal opacity at birth. It has been subdivided into type I and type II [2]. Type I PA is characterized by iridocorneal adhesions, and type II PA is recognized by central corneal opacity with cataracts or corneolenticular adhesions Our case is a severe form of PA with both iridocorneal and corneolenticular adhesions. The systemic involvement with PA can vary. The term Peters plus syndrome refers to PA associated with cleft lip/palate, short stature, abnormal external ears and mental retardation [2]. The systemic anomalies of Peters plus syndrome can be detected by prenatal image study like sonography, [3], but PA type I and type II, owing to being characterized by localized ocular abnormalities, were never reported with prenatal image diagnosis. In our case, the opacity of fetal eyeballs was found under sonographic examinations at the gestational age of 20 weeks, and the following MRI investigation revealed no other anomalies, thereby rendering Peters plus syndrome an unlikely diagnosis. Thus, the opacity of fetal eyeballs as detected by prenatal ultrasound not only served as a clue to congenital cataract, but to PA as well, in spite of its rarity. However based on ultrasound images, it is difficult to distinguish between the opacity of cornea and the cloudiness of the lens. Even fetal MRI has no role to play in this regard. Consequently, in our case, it was rather difficult to make a definite diagnosis of PA prenatally.

In literature, there was ever one discordant donor PA reported in a TTTS case, [7] where the PA was diagnosed after delivery without a prenatal image. TTTS is a complication of monochorionic twin pregnancies, so both fetuses share nearly the same genetic make-up; the concordance rate for any birth defect is higher in monozygotic twin pairs compared with dizygotic twin pairs [8]. Though a portion of PA had been reported associated with a genetic abnormality, [1] a majority of cases lack a genetic diagnosis [4]. Judging from our case and previous reports on the discordant PA in monochorionic twins, [7] we suspected epigenetic factors may play a part in the occurrence of PA. In our case and previous cases reported [7], the affected PA fetuses in TTTS were both donor twins; donor twins usually have relative hypotension and hypo-perfusion than recipient co-twin due to unequal placenta sharing and imbalanced intertwin perfusion. So hypo-perfusion from the placenta could pose as one epigenetic cause of PA. Other epigenetic factors like different activation of maternal and paternal genes, [9] or genetic defects with de-novo mutations in one twin after splitting [10] should also be considered. In the absence of a molecular study, a future genetic workup may be proposed to the families to evaluate if any genetic causes of PA were involved in this case.

The strength of this case report is presenting prenatal ultrasonography images of isolated PA (Type I or II PA), that have not been reported before, and also revealing a discordant malformation in one monozygotic twin leads us to speculate that the origin of PA in this case may be due factors that have an epigenetic root. The weakness 
of this report is that without molecular study, whether there is a genetic cause for PA in this case couldn't be ruled out.

In conclusion, our case has demonstrated PA should be placed among the differential diagnoses when prenatal ultrasound image revealed opacity of fetal eyeballs. Discordant PA in monochorionic twins highlights the possibility of an epigenetic cause of PA in these rare cases.

\section{Abbreviations}

PA: Peters anomaly; TTS: Twin-twin transfusion syndrome; MVP: Maximum vertical pocket; MC: Monochorionic; UA: Umbilical artery; MRI: Magnetic resonance imaging

\section{Acknowledgements}

We are grateful for the funding provided by Chang Gung Memorial Hospital, Linkou Medical Center (CMRPG3H1791).

\section{Authors' contributions}

YLC, ASC, SDC and MCC designed the research. YLC, ASC, CYC, SDC, YSL and MCC participated in collecting the data. All authors contributed to the drafting or revising of the manuscript, approved this final version to be published, and are willing to take public responsibility for the accuracy and integrity of its content.

\section{Funding}

This work was supported by a grant (CMRPG3H1791) from Chang Gung Memorial Hospital, Linkou Medical Center. The role of the CMRPG3H1791 grant was to support the language editing of the paper and data collection.

\section{Availability of data and materials}

The datasets obtained and/or analyzed during the current study are available.

from the corresponding author on reasonable request.

\section{Ethics approval and consent to participate}

The study was approved by the Institutional Review Board of the Chang Gung Memorial Hospital (202000867B0).

\section{Consent for publication}

Consent for publication: written informed consent was obtained from the patient for publication of this case report. Documentation of the written consent will be provided to the journal upon request.

\section{Competing interests}

The authors declare that they have no competing interests.

\section{Author details}

'Department of Obstetrics and Gynecology, Chang Gung Memorial Hospital, Chang Gung University College of Medicine, Tao-Yuan, Taiwan. ${ }^{2}$ Department of Obstetrics and Gynecology, Cathay General Hospital, Hsinchu, Taiwan. ${ }^{3}$ Department of pediatrics, Chang Gung Memorial Hospital, Chang Gung University College of Medicine, Tao-Yuan, Taiwan. ${ }^{4}$ Department of Ophthalmology, Chang Gung Memorial Hospital, Linkou, Taiwan.

Received: 31 May 2020 Accepted: 18 September 2020

Published online: 23 September 2020

\section{References}

1. Bhandari R, Ferri S, Whittaker B, Liu M, Lazzaro DR. Peters anomaly: review of the literature. Cornea. 2011;30(8):939-44.

2. Zaidman GW, Flanagan JK, Furey CC. Long-term visual prognosis in children after corneal transplant surgery for Peters anomaly type I. Am J Ophthalmol. 2007;144(1):104-8.

3. Canda MT, Doganay Caglayan L, Demir AB, Demir N. Prenatal detection of Peters plus-like syndrome. Turk J Obstet Gynecol. 2018;15(4):273-6.
4. Weh E, Reis LM, Happ HC, Levin AV, Wheeler PG, David KL, Carney E, Angle $B$, Hauser N, Semina EV. Whole exome sequence analysis of Peters anomaly. Hum Genet. 2014;133(12):1497-511.

5. Chang YL, Chao AS, Chang SD, Li WF, Cheng PJ. Predisposing factors and neonatal outcomes for twin-twin transfusion syndrome cases developing transient donor hydrops after fetoscopic laser coagulation: a case control study. BMC Pregnancy Childbirth. 2019;19(1):87.

6. Matsubara A, Ozeki H, Matsunaga N, Nozaki M, Ashikari M, Shirai S, Ogura Y. Histopathological examination of two cases of anterior staphyloma associated with Peters' anomaly and persistent hyperplastic primary vitreous. Br J Ophthalmol. 2001;85(12):1421-5.

7. Mondino BJ, Shahinian L Jr, Johnson BL, Brown SI. Peters' anomaly with the fetal transfusion syndrome. Am J Ophthalmol. 1976;82(1):55-8.

8. Ooki S. Concordance rates of birth defects after assisted reproductive technology among 17258 Japanese twin pregnancies: a nationwide survey, 2004-2009. J Epidemiol. 2013;23(1):63-9.

9. Jorgensen AL, Philip J, Raskind WH, Matsushita M, Christensen B, Dreyer V, Motulsky AG. Different patterns of $\mathrm{X}$ inactivation in MZ twins discordant for red-green color-vision deficiency. Am J Hum Genet. 1992;51 (2):291-8.

10. Tang J, Fan Y, Li H, Xiang Q, Zhang DF, Li Z, He Y, Liao Y, Wang Y, He F, et al. Whole-genome sequencing of monozygotic twins discordant for schizophrenia indicates multiple genetic risk factors for schizophrenia. J Genet Genomics. 2017;44(6):295-306.

\section{Publisher's Note}

Springer Nature remains neutral with regard to jurisdictional claims in published maps and institutional affiliations.

\section{Ready to submit your research? Choose BMC and benefit from:}

- fast, convenient online submission

- thorough peer review by experienced researchers in your field

- rapid publication on acceptance

- support for research data, including large and complex data types

- gold Open Access which fosters wider collaboration and increased citations

- maximum visibility for your research: over $100 \mathrm{M}$ website views per year

At BMC, research is always in progress.

Learn more biomedcentral.com/submissions 